\title{
Whose education counts? The impact of grown children's education on the physical functioning of their parents in Taiwan
}

Zachary Zimmer Population Council

Albert I. Hermalin

Hui-Sheng Lin

Follow this and additional works at: https://knowledgecommons.popcouncil.org/departments_sbsr-pgy

Part of the Demography, Population, and Ecology Commons, Education Commons, Family, Life Course, and Society Commons, and the International Public Health Commons How does access to this work benefit you? Let us know!

\section{Recommended Citation}

Zimmer, Zachary, Albert I. Hermalin, and Hui-Sheng Lin. 2001. "Whose education counts? The impact of grown children's education on the physical functioning of their parents in Taiwan," Policy Research Division Working Paper no. 146. New York: Population Council. Version of record: https://doi.org/ 10.1093/geronb/57.1.S23 


\section{Whose Education Counts? The Impact of Grown Children's Education on the Physical Functioning of Their Parents in Taiwan}

Zachary Zimmer Albert I. Hermalin $H$ ui-Sheng Lin 


\title{
Whose Education Counts? \\ The Impact of Grown Children's Education on the Physical Functioning of Their Parents in Taiwan
}

\author{
Zachary Zimmer \\ Albert I. Hermalin \\ Hui-Sheng Lin
}

Zachary Zimmer is Research Associate, Policy Research Division, Population Council. Albert I. Hermalin is Professor Emeritus of Sociology and Research Associate, Population Studies Center, University of Michigan. Hui-Sheng Lin is Senior Researcher, National Institute of Family Planning, Taichung, Taiwan. Correspondence should be addressed to: Zachary Zimmer, Population Council, One Dag Hammarskjold Plaza, New York, NY 10017. E-mail: zzimmer@popcouncil.org.

An earlier version of this paper was presented at the Asia-Pacific Regional Conference for the International Year of Older Persons in Hong Kong, April 1999. This research is supported by the National Institutes of Health-National Institute on Aging Research Grant number 1 R03 AG17270-01. 


\begin{abstract}
Research has identified education as an important predictor of physical functioning in old age. Older adults in Taiwan tend to experience close ties to family members and high rates of adult child coresidence, much more so than is typical in Western cultures. These circumstances might imply additional health-related benefits stemming from the education of grown children. This association could arise in a number of ways, for instance through the sharing of health-related information between child and parent, the quality of caregiving efforts, monetary assistance for medical and other services, or through other psychosocial avenues. In this study, a nationally representative survey of older Taiwanese is employed to examine these concurrent effects. Outcome variables include the existence of any functional limitations (dichotomously measured) and the severity of functional disorders (ordinally measured). Dichotomous and ordinal logistic models are employed. Results suggest that, after adjusting for age, sex, and other factors, both child's and parent's education have an impact on the existence of physical limitations; however, the child's education is more important than the parent's in predicting severity of limitations. This finding implies that models ignoring social network characteristics in the effort to determine health outcomes of older adults may be misspecified, at least in some non-Western societies.
\end{abstract}

This material may not be reproduced without written permission from the authors. 
"A family is more than just a collection of people who might expose each other to infections and pollutants. A family is an economic unit bound by emotional ties. It is in the household that the larger social and economic order impinges on individuals, exposing them to varying degrees of hardship, frustration and struggle" (Ross et al. 1990, p. 1059). This observation illustrates the principle that family members interact and influence one another in a multitude of ways, and that these interactions and influences shape their life experiences. Some debate has occurred about the nature of the family in American society (Silverstein and Bengston 1997; Luescher and Pillemer 1998), but in a number of societies the existence of high degrees of family cohesion, interaction, coresidence, and reciprocity is less debatable. The potential for interactions between families and between individuals within families is substantial throughout much of the world.

Overlooking the influences of family interactions can result in limited insights into the factors that determine health. The current research, conducted in Taiwan, derives from an extensive tradition of study documenting an inverse association between socioeconomic status and health. Although there are some recent exceptions (Robert and Li 2001), research examining the socioeconomic determinants of health among older adults usually employs what can be called an individualistic perspective that ignores the attributes of a wider social network. In this study, we seek to answer the question whether the education of a grown child influences the physical functioning of his or her elderly parents in addition to or beyond the effects of the older adult's own level of education. If so, what aspects of the elderly parent's physical functioning are influenced by the child's education? To answer these questions, we examine the influence of both parents' and children's education on the probability that an elderly parent has functional limitations and on the severity of those limitations.

A voluminous body of social science research examines the impact of social stratification on health, although most of this research concerns populations in the United States and Britain. By reviewing empirical evidence garnered over several decades that shows a robust association between class and mortality, Antonovsky (1967) helped initiate the modern discourse on the topic. His review was followed by extensive studies of the effect of individual socioeconomic characteristics on health and mortality in the United States and England (Kitagawa and Hauser 1973; Marmot et al. 1978). More 
recently, attention in Western industrialized countries has turned to an investigation of the changing trends in socioeconomic status and health over time (Townsend and Davidson 1982; Pappas et al. 1993; Preston and Elo 1995), and to the causal mechanisms and intervening factors that place those of lower socioeconomic status at a disadvantage (Williams 1990; House et al. 1994; Link and Phelan 1995; Ross and Wu 1995). With respect to elderly populations, some evidence exists of convergence in rates of mortality and chronic disorders by levels of education (House et al. 1990; Elo and Preston 1995). Convincing evidence indicates that significant differentials in a variety of physical functions are maintained into old age (Duffy and MacDonald 1990; Rogers et al. 1992; Guralnik et al. 1993; Camacho et al. 1993; Kaplan et al. 1993). Such differences may reflect the cumulative impact of education throughout life (Ross and Wu 1996; Lynch et al. 1997).

Most of the studies noted above focus on the socioeconomic characteristics of the indexed individual, and differentials in health are explained as a function of personal characteristics, including the person's knowledge of disease prevention, access to medical care, personal behaviors, and psychological dimensions such as stress and feelings of self-efficacy. Health crises and existing medical conditions tend to involve family networks in many ways, however. Grown children may not only assume caretaking roles but they may also bring considerable financial knowledge and management resources to bear upon decisions about the timing and quality of health care and subsequent actions. Thus, studies of the influence of socioeconomic status on health that focus solely on the individual respondent's attributes may misspecify the determinants of health for older adults.

\section{The TAIWAN SETTING}

Because of its Confucian culture and the implications of that culture for intergenerational support and familial cohesion, Taiwan represents an ideal setting in which to study the impacts of the educational attainment of grown children on their aging parents' health. The Chinese who originally settled in Taiwan in the seventeenth century brought with them a family system based on extended households and the notion of the family as a corporate unit (Hermalin et al. 1996). This unit is organized 
around a collective economy whereby earnings are pooled and used to provide support for all family members. This notion extends beyond economics to providing assistance with household maintenance and caregiving. Good reasons can be found to presume that the influence of children on parents' health would be substantial in this sort of system where the care of elders is the obligation of all family members and where the family is understood to be the most natural entity through which to provide care for older adults. The system leads to a pooling of material and informational resources and, in a practical sense, translates into a variety of health-related functions performed by members of the family. Family members can provide a great deal of personal care, including paying for medical costs, assisting elders in daily activities, and providing social interaction and recreation for aged members. The physical proximity of much of one's social network allows the efficient transfer of family resources. Moreover, a grown child's health-related knowledge and access to medical care, factors that relate to his or her educational attainment, become important to the health of older parents.

Since World War II, Taiwan has been transformed from a rural to a primarily urban society with a highly developed economic infrastructure. Substantial reductions in fertility and increases in life expectancy over the last couple of decades have resulted in a rapidly aging society. Yet the cohesiveness of the family appears to have remained intact despite these changes. Household size, although decreasing slightly over time, remains large, and little evidence is seen of changes in the living arrangements of the elderly (Asis et al. 1995). More important, intergenerational support remains strong within a number of economic and caregiving domains (Hermalin et al. 1992).

An additional change, noteworthy in the context of this study, is the rapid rise in educational attainment and the diminution of the gender gap in education over the last several decades. College attendance for males rose from about 2 percent to about 29 percent between 1952 and 1988, whereas for females the increase was from less than 1 percent to about 33 percent during the same time period (Hermalin et al. 1996). As a result, the current generation of older adults has educational levels well below those of their children. Children are now exposed to new beliefs and expanding knowledge that may alter and increase the resources available for the care of their aging parents (Cornman et al. 1996). Here, we examine whether grown children bring these resources to bear on 
the caretaking of their parents by testing the impact of their education after adjusting for the characteristics of their parents.

\section{METHODS}

The data for this study are drawn from the 1989 Survey of Health and Living Status of the Elderly in Taiwan. A large sample of older Taiwanese was selected randomly to make this a nationally representative survey. Adults aged 60 and older by the end of 1988 were considered to be the sample universe. One of every 370 older adults living in Taiwan was selected for study, resulting in interviews of 4,049 individuals. The response rate was 92 percent. Of the respondents, 3,795 had at least one living child, and the analysis is restricted to these individuals. The main aim of this project was to collect information useful in analyzing the influence of rapid social and economic change on the elderly in Taiwan. The survey itself is extensive, including questions about the physical health and sociodemographic characteristics of the respondent, as well as sociodemographic information about all coresident and noncoresident children. This data source is, therefore, ideal for comprehensive testing of the relationship between education and functional status as well as of the possible influences of social network members. More information about this survey can be found in the first research report published as part of the project (Taiwan Provincial Institute of Family Planning 1989).

\section{Measuring physical functioning}

Functional health can be defined as the ability to conduct tasks such as activities of daily living or ADLs (Katz et al. 1963), instrumental activities of daily living or IADLs (Lawton and Brody 1969), or tasks involving general upper and lower body movements (Nagi 1976; Crimmins and Saito 1993). The measurement of some of these types of tasks, particularly the instrumental activities, can be confounded by role expectations and living environments (Verbrugge and Jette 1994; Freedman and Martin 1998; Simonsick et al. 2001). For instance, the answer to a question such as, "Do you have any problem shopping for things?" may depend, to some degree, on the distance the respondent needs to travel in order to shop or on who tends to be responsible for shopping. Nagi (1976 and 1991) defined three states of physical dysfunction. "Impairment" refers 
to having a physical problem, such as an arthritic condition. "Functional limitation" refers to the inability to perform specific physical movements because of the impairment, and "disability" refers to the inability to perform daily tasks such as shopping or doing housework, because of the limitation (Kelly-Hayes et al. 1992). In this study, we limit measures of physical functioning to those that indicate limitations- that is, those involving upper or lower body movement. By focusing on limitations, we seek to avoid a consideration of the social biases that can relate to disability. Specifically, we focus on the ability to crouch, climb stairs, walk, grasp, and reach for things. A number of other activities that appear in the data, such as performing housework, are omitted because responses may reflect role expectations and particular living environments, as noted above. Other items, such as lifting objects and standing for a period of time, are omitted because of a large number of missing responses. Many individuals responded that they never performed these tasks and therefore could not assess their ability to do so.

Our conceptualization of functional limitations assumes two distinct measures. All ailments, whether they are chronic conditions or temporary illnesses, can be measured dichotomously, indicating the existence or absence of the ailment, or by using an ordinal level scale, indicating the severity of the ailment. For instance, with respect to functional capacity, we can measure first the existence of any functional limitations and second, for those who have limitations, we can measure their severity. Many individuals, even at older ages, are not troubled by functional limitations. For those who are, severity varies. In terms of education, this assumes two questions. First, how does education influence the probability of experiencing a functional limitation? Second, how does education influence the severity of such limitations for those who have them? If education has differential effects on existence versus severity, then combining those two concepts into a single measure will distort the separate effects. For this reason, we construct two functional outcome measures as described above.

Table 1 provides the percentage distribution of respondents' reports of experiencing functional limitation according to four possible response categories. This table is organized from the most difficult task to the easiest according to the proportion reporting no difficulty. The most frequently reported difficulties are crouching, with about 27 percent reporting at least a little difficulty, and climbing stairs, with about 26 percent 
Table 1 Percentage distribution of older adults' reports of difficulty in performing functional tasks by level of difficulty, Taiwan items

\begin{tabular}{lccccr}
\hline Task & $\begin{array}{c}\text { No } \\
\text { difficulty }\end{array}$ & $\begin{array}{c}\text { A little } \\
\text { difficulty }\end{array}$ & $\begin{array}{c}\text { A lot of } \\
\text { difficulty }\end{array}$ & $\begin{array}{c}\text { Cannot } \\
\text { perform } \\
\text { the task }\end{array}$ & Total \\
\hline Crouching & 73.3 & 12.9 & 6.8 & 6.9 & 100.0 \\
Climbing stairs & 73.9 & 15.3 & 5.4 & 5.5 & 100.0 \\
Walking & 80.0 & 10.4 & 5.0 & 4.6 & 100.0 \\
Grasping & 91.7 & 4.5 & 1.7 & 2.2 & 100.0 \\
Reaching & 92.6 & 3.7 & 1.4 & 2.2 & 100.0 \\
\hline
\end{tabular}

reporting at least a little difficulty. On the other hand, more than 90 percent of respondents report no difficulty in grasping or reaching. A factor analysis of these items (not shown) indicated that they load highly onto a single factor (eigenvalue of 3.5), and the Cronbach's Alpha coefficient for this group of items is 0.89 . These values suggest that they represent a single construct.

Respondents who report at least a little difficulty with one or more of the five functional tasks are considered as having a functional limitation and are given a code of 1 with respect to the "existence of functional limitation" variable. Others are given a code of 0 . To construct a severity variable, we examine the specific responses to the five items and determine whether the limitations reported are mild, moderate, or severe. Those reporting only "a little difficulty" with only one or two tasks are considered to have mild limitations. Those individuals reporting that they have "a lot of difficulty" with one or two tasks, or that they "cannot perform" one or two functional tasks, or those individuals reporting that they have "a little difficulty" with more than two functional tasks, are coded as having moderate limitations. Finally, those individuals reporting that they have "a lot of difficulty" with three or more tasks or that they "cannot perform" three or more functional tasks are coded as having severe limitations. Of those who report experiencing at least one limitation, 43 percent are coded as mild, 38 percent as moderate, and 19 percent as severe (not shown).

Other measures that have been used in the past to indicate degree of severity include number of limitations reported and a composite scale in which points are as- 
signed for no difficulty, some difficulty, or a lot of difficulty or "cannot perform the task," with the points then summed across available items. Although these types of measures are referred to frequently in the literature, no single measure is a faultless way of determining severity. For instance, an individual may have a large number of limitations, but if he or she reports having only a little difficulty with each task, the total number of limitations may not be indicative of severity. Similarly, points that are arbitrarily assigned to response categories, say a score of 1 for "a little difficulty" and a score of 2 for "a lot of difficulty," may not reflect a true difference in severity. In this example, having a lot of difficulty may not be twice as severe as having a little difficulty. Yet all of these scales are highly correlated and represent a similar construct. In the current data, there is a 0.94 Pearson's correlation between the number of limitations and the ordinal severity scale, and a 0.89 correlation between a score using a summed scale and the ordinal severity scale. Furthermore, sensitivity tests suggest that our conclusions do not differ when these other scales are used. The choice of severity measure is, therefore, based on preference and on relation to the particular research task. We employ the ordered measure because we are interested in capturing a qualitative degree of difference in severity while employing categories that best parallel the response categories of the original items.

\section{Covariates}

Education has been shown to be related to knowledge and understanding of disease processes, to means of prevention, to health-promoting practices, and to self-esteem and sense of control. It is a consistent measure of socioeconomic status, remaining constant throughout adulthood for most individuals. It is also a relatively accessible and reliable measure. Individuals know their own level of education, and most can report their children's level of education accurately. This measure contrasts with income, for example, which may be accrued in a variety of ways, changes throughout life, and is subject to high levels of reporting error, particularly in reports of the income of family members other than the respondent. These considerations have led a number of researchers to consider education as the aspect of socioeconomic status most important to health (Winkleby et al. 1992; Ross and Wu 1995). 
Education is measured as a categorical variable that reflects low, middle, and high levels of attainment for the respondent and for his or her best-educated child. Because educational attainment increased substantially over the course of a generation in Taiwan, the years of education reflecting low, middle, and high attainment differ between parents and children. For parents, those with low education are considered to have no formal schooling; those with primary education are coded as having middle education; and those with more than primary schooling are considered to have a high level of education. For children, those with low education are considered to lack primary schooling; those who reach junior or senior high are coded as having middle education; and those with at least some college are coded as having a high level of education.

Family size in Taiwan tends to be large, and each child has the potential to influence his or her parents throughout the life course. Ideally, the characteristics of each child should be brought to the model, but except for considering some composite of all children's education, this type of modeling is complex and difficult to interpret. In order to capture family resources available through children, we consider the educational attainment of the child educated to the highest level. This strategy has at least two advantages. First, a fair amount of homogeneity is generally found in the educational attainment of all children within a household, so that the best-educated child is a good proxy for the education of all the children. Second, the health of an older adult is likely to be most influenced by the child who has the greatest resources available, and this influence is well represented by selecting the child with the most education as an indicator. We note, however, that rather than indicating the education of a selected child, our measure can be considered as a general indicator of resources that may be available to parents through their offspring.

Because more than one child within a family can have the same level of education, distinguishing a single child who has the highest level may not be possible in many instances. By determining the children who tie with the highest level of education, however, we can construct other variables of importance. First, we determine the sex of the best-educated child or children. The sex of children is important because boys are thought to have potentially greater earning power than girls, and parents may rely disproportionately on their male offspring for financial support and on the wives of male offspring for 
physical support in day-to-day activities (Hermalin et al. 1996). For cases in which one child has the highest level of education among all children in a household, or two children of the same sex are the most educated, we code the specific sex of the individual child or children. For cases in which at least one male and at least one female child has the same high level of education, we code the sex as "male and female." We construct dummy variables to test for the influence of the sex of the child, with female being the reference category. In a similar vein, we measure the proximity of child to parent with regard to living arrangements. It is reasonable to expect that the education of a child who is coresident with a parent will be more influential for that parent's well-being than the education of a child living farther away. If two or more children have equally high levels of education, we consider the proximity of the child living closest to the parent. Proximity for the best-educated child or children is coded into three categories: coresiding, living nearby (in the same community, village, or town), or living farther away, with the last being the reference category.

We also consider a set of covariates related to the demographic characteristics of the parent that are expected to influence his or her physical functioning. Age is an important correlate of health; those who are older are expected to have a higher probability of reporting physical limitations. We adjust for sex of respondent because women have been shown to be more likely to suffer from functional disorders at older ages (Verbrugge 1989). Because access to medical facilities may differ between rural and urban areas, we include rural-urban residence in our models. Marital status has been shown to influence health in a number of ways, such as forms of mutual support (Ortmeyer 1974; Goldman et al. 1995). We consider marital status as a dichotomous variable, that is, "married" versus "other." Taiwan is fairly homogenous ethnically, but an important distinction is made between "mainlanders" and others. Mainlanders are those who migrated to Taiwan from China after World War II. They are predominantly male soldiers and officials and have distinct social and behavioral characteristics that warrant particular attention (Hermalin et al. 1996). For instance, mainlanders are more likely to be employed in the government, to be unmarried, and to have higher incomes than are other Taiwanese. Because they were soldiers, mainlanders may have higher fitness levels than others, and they may consequently have fewer functional limitations. Our ethnicity variable, there- 
fore, contrasts mainlanders with others. We also include a measure of total number of children in our model in order to account for the overall availability of support from children.

Finally, in order to adjust results for level of economic well-being and to assure that influences of education are not due strictly to wealth, we include a measure of household income. This information is gleaned from the question, "At present, what is the total money income you (and your spouse) receive in a month?" The survey recorded responses categorically, and we create an income variable with five categories. Those in the lowest category earn less than 5,000NT (new Taiwan dollars, approximately US $\$ 150$ ) per month. The other categories are 5,000 to $9,999 \mathrm{NT}, 10,000$ to $19,999 \mathrm{NT}$, and 20,000NT or more per month. Despite the categorical nature of the question, about 13 percent of surveyed individuals did not report their income. Rather than imputing a value for these individuals, those with missing income are considered as a fifth category, and we examine whether they have different functioning outcomes than others. Distributions and coding schemes for all the variables involved in the analysis are provided in Table 2 .

\section{Statistical analysis}

The two outcome measures suggest a two-part analytical approach. According to Manning et al. (1987), a two-part strategy is also appropriate when zero values are considered to be true zeros rather than censored cases. This is the case in the present analysis, because an individual without a physical limitation has the value of a true zero with respect to severity and, therefore, is omitted from the second part of the analysis. The model used here is depicted in Figure 1. In the first set of equations, we examine the effects of covariates on having a limitation, using the entire sample. In the second set of equations, we limit analyses to the approximately 1,400 cases reporting at least one limitation and examine effects of covariates on severity of the limitation.

Models are constructed hierarchically. We examine first the impact of the parent's education. Next, in order to view the additional influences of the child, we add child's education to the model and thereby adjust parent's and child's education simultaneously. We then add the covariates that relate to the child or children, including their sex and 
Table 2 Coding scheme of variables and percentage distribution based on data from the Survey of Health and Living Status of the Elderly in Taiwan, 1989

\section{Variable/coding}

Existence of a functional limitation

$$
0=\text { no }
$$$$
1=\text { yes }
$$

\section{Percentage distribution}

Functional limitation severity

$$
\begin{aligned}
& 1=\text { mild } \\
& 2=\text { moderate } \\
& 3=\text { severe }
\end{aligned}
$$

Education of parent

$$
\text { Low }=\text { none }(r)
$$

Middle $=$ primary

High $=$ primary +

Education of child

Low $=$ No more than primary $(\mathrm{r})$

19.1

Middle $=$ Junior/senior high

High $=$ College

Sex of best-educated child

Female (r)

Male

39.0

Male and female

45.8

Child's proximity to parents

Coresident

61.3

Lives nearby (same community or town)

16.6

Lives farther away (in different town or out of country) (r)

22.1

Sex

$$
\begin{aligned}
& 0=\text { Male } \\
& 1=\text { Female }
\end{aligned}
$$

Residence

$0=$ Urban

$1=$ Rural

Marital status

$0=$ Other

$1=$ Married

Ethnicity

$0=$ Other

1 = Mainlander

19.0

Household income

Lowest (less than 5,000NT per month)

Second (5,000-9,999NT per month)

Third (10,000-19,999NT per month)

15.6

Highest (20,000NT + per month)

13.3

Missing response

Age (measured continuously)

Mean $=68.3$ Standard deviation $=6.50$

Number of living children (measured continuously)

Mean $=4.83$ Standard deviation $=2.15$

$(\mathrm{r})=$ Reference category. $\quad 5,000 \mathrm{NT}=$ approximately US $\$ 150$. 
Figure 1 Model for testing the impact of education on functional status of older adults in Taiwan

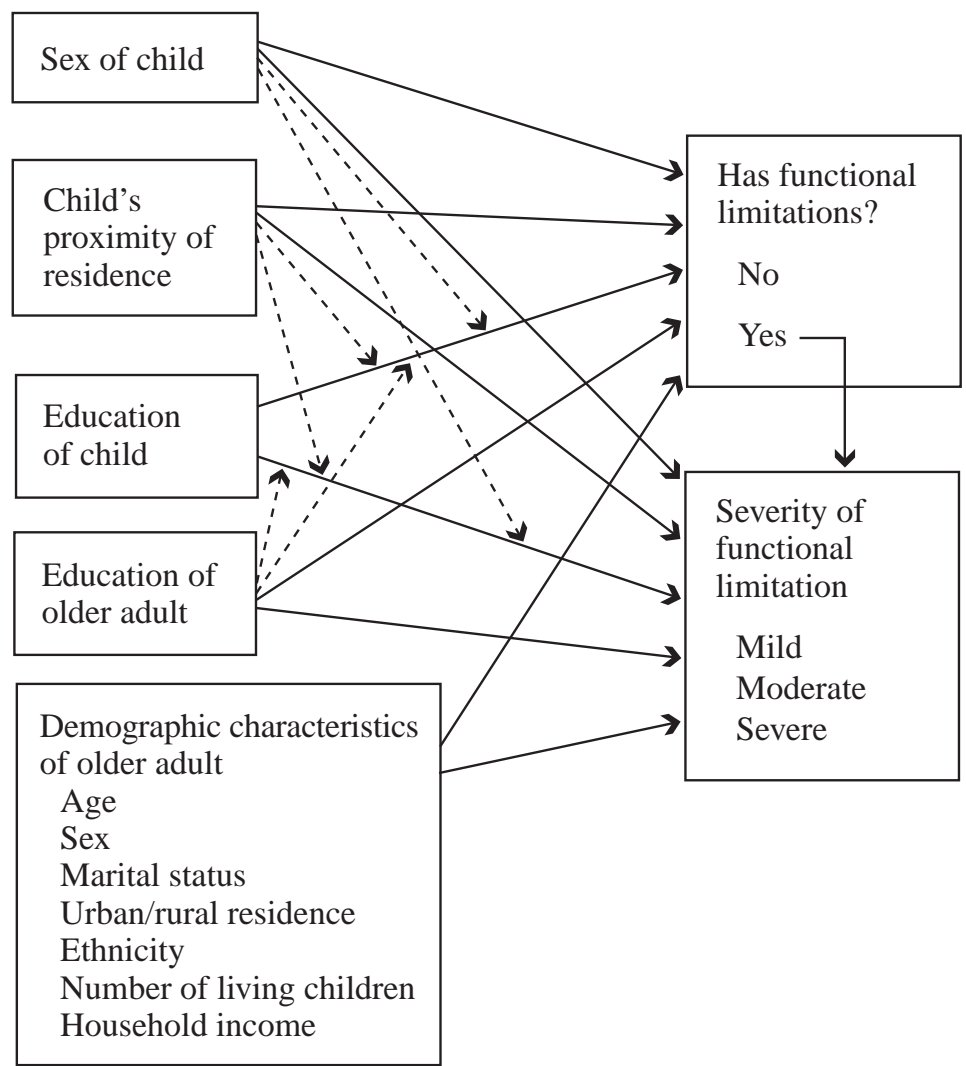

proximity of residence. Finally, we consider interaction effects that could influence the way in which child's education influences the functional limitation status of the parents. In the figure, dashed lines indicate these interactions. The interaction effects tested include sex of child with education of child, proximity of residence of child with education of child, and education of respondent with education of child.

For the first part of the analysis, we use logistic regression and assume that the probability of the existence of a limitation can be calculated as: 


$$
\operatorname{Pr}\left(y_{j}=1 \mid X_{j}\right)=\left\{\exp \left(\beta_{1} x_{1 j}+\beta_{2} x_{2 j}+\ldots \beta_{k} x_{k j}\right)\right\} /\left\{1+\exp \left(\beta_{1} x_{1 j}+\beta_{2} x_{2 j}+\ldots \beta_{k} x_{k j}\right)\right\},
$$

where $\beta$ is the coefficient derived from the logistic model, $\exp$ is the exponent, and $\operatorname{Pr}$ is the probability. In the second part, we use a cumulative, ordered, logistic-regression approach (Agresti 1996), which has the following form for predicting the probability of membership in any group:

$$
\operatorname{Pr}\left(\text { outcome }_{j}=i\right)=\operatorname{Pr}\left(k_{i}-1<\beta_{1} x_{1 j}+\beta_{2} x_{2 j}+\ldots \beta_{k} x_{k j}+\mu_{j} \leq k_{i}\right),
$$

where $k$ is the cut-point between any two groups, $\beta$ is the coefficient derived from the ordered logistic model, and $\mathrm{Pr}$ is the probability. The ordinal logistic model is proportional in that it assumes that the log odds are similar when dividing the ordered variable into any two parts. For instance, in a three-category ordered variable, coefficients represent the change that a one-unit increase in an independent variable has on the log odds of membership in group one versus group two or three, or group one or two versus group three. Probabilities are predicted based on one set of coefficients and a number of constants, usually referred to as cut-points, where the number of constants is the number of categories in the ordered variable minus one.

\section{RESULTS}

We begin the analysis by examining the association of education with the existence of any functional limitation. Model 1 in Table 3 shows that, in addition to age and sex, the level of education of the elderly parent, entered separately, is a statistically significant determinant of the existence of any limitations. This is the standard finding when adopting an individualistic approach to modeling the functional health of an older adult. For example, our odds ratios show that older adults who have a high level of education (that is, more than primary schooling) are 53 percent less likely to report a functional limitation compared with those having a low level of education.

Model 2 shows that effects of both parent's and child's characteristics are substantial and statistically significant predictors of having a functional limitation, adjusting for other sociodemographic covariates. Comparing Model 1 with Model 2, the effect of parent's education is reduced. The odds ratios change from 0.72 to 0.77 when the older adult has a mid-level education in comparison with having only primary schooling, and from 0.47 to 0.54 when the older adult has a high level of education in compari- 
Table 3 Logistic regression adjusted odds ratios for the existence of any functional limitations among older adults, Taiwan $(\mathrm{N}=3,726)$

\begin{tabular}{|c|c|c|c|}
\hline Variable & Model 1 & Model 2 & Model 3 \\
\hline \multicolumn{4}{|l|}{ Respondent's education } \\
\hline Low $(r)$ & 1.00 & 1.00 & 1.00 \\
\hline Middle & $0.72^{* *}$ & $0.77^{* *}$ & $0.78^{* *}$ \\
\hline High & $0.47^{* *}$ & $0.54^{* *}$ & $0.58^{* *}$ \\
\hline \multicolumn{4}{|l|}{ Child's education } \\
\hline Low (r) & - & 1.00 & 1.00 \\
\hline Middle & - & 0.88 & $0.80^{*}$ \\
\hline High & - & $0.69^{* *}$ & $0.61^{* *}$ \\
\hline \multicolumn{4}{|l|}{ Sex of best-educated child } \\
\hline Female (r) & - & - & 1.00 \\
\hline Male & - & - & 1.35 \\
\hline Male and female & - & - & 0.87 \\
\hline \multicolumn{4}{|l|}{ Child's proximity to parent } \\
\hline Lives farther away (r) & - & - & 1.00 \\
\hline Coresides & - & - & 0.87 \\
\hline Lives nearby & - & - & 0.90 \\
\hline Age & $1.08^{* *}$ & $1.08^{* *}$ & $1.08^{* *}$ \\
\hline $\operatorname{Sex}(1=$ female $)$ & $1.75^{* *}$ & $1.81^{* *}$ & $1.82^{* *}$ \\
\hline Marital status $(1=$ married $)$ & 1.07 & 1.08 & 1.09 \\
\hline Residence (1 = rural) & 0.90 & 0.89 & 0.89 \\
\hline Ethnicity (1 = mainland) & 1.21 & 1.25 & 1.24 \\
\hline Number of living children & 0.97 & 0.98 & 1.00 \\
\hline \multicolumn{4}{|l|}{ Income } \\
\hline Lowest (r) & 1.00 & 1.00 & 1.00 \\
\hline Second & $0.70^{* *}$ & $0.73^{* *}$ & $0.73^{* *}$ \\
\hline Third & $0.52^{* *}$ & $0.55^{* *}$ & $0.55^{* *}$ \\
\hline Highest & $0.42^{* *}$ & $0.46^{* *}$ & $0.46^{* *}$ \\
\hline Missing & 1.21 & 1.23 & 1.23 \\
\hline-2 Log likelihood & $4,241.0$ & $4,229.7$ & $4,222.5$ \\
\hline
\end{tabular}

son with a low level. Apart from parent's education, however, child's education appears to have an additional effect. For example, the odds ratio for having a physical limitation for those with high versus low child's education is 0.69 , meaning that parents whose child has a high education are 31 percent less likely to report a limitation compared with those whose best-educated child has primary schooling or less. Log-likelihood results 
indicate that each education measure, that of the elderly parent and of the child is an independently significant factor in determining the probability of reporting a functional limitation net of each other.

Model 3, examining whether proximity of residence or sex of child makes a difference with respect to functional limitations of the elderly parent, shows little improvement in log likelihood, and the added coefficients are not statistically significant. This finding indicates that with respect to having a functional limitation, having a child who lives farther away, rather than coresiding or living nearby, and having the child or children with the highest education be female, rather than male or both male and female, do not matter.

Table 4 presents odds ratios from ordinal logistic-regression models that predict the severity of functional limitation for older adults who report difficulty performing at least one functional task. Looking first at Model 1, the education of the older adult has some negative associations with the severity of physical limitations, but the coefficients are not statistically significant. This result is surprising and is different from that found when the existence of any limitation is considered. Model 2 indicates that the education of the best-educated grown child does, indeed, have a statistically significant impact on severity of limitations over and above the effect of parent's education. The odds ratios for middle and high levels of education are less than 1.00, indicating that for cases in which the education of the child is "high," the probability that limitations are more severe decreases by a statistically significant and substantial amount. For example, odds ratios suggest that when the child's level of education is high, the probability that a parent will have severe physical limitations decreases by about 31 percent in comparison with a situation in which the child's educational level is low. Therefore, only the addition of the child's education significantly enhances the predictive power of the model, and child's education adds some influence to the outcome of physical limitation beyond that of the older adult's education, but parent's education does not add to the model net of his or her other sociodemographic characteristics.

Adding child's sex and proximity of residence to the model shows results in predicting severity of limitation similar to those shown in predicting the existence of any limitations, that is, these effects are not statistically significant. Where the child lives 
Table 4 Ordered logistic regression adjusted odds ratios for severity of functional limitation for older adults reporting at least one functional limitation, Taiwan $(\mathrm{N}=1,369)$

\begin{tabular}{|c|c|c|c|}
\hline Variable & Model 1 & Model 2 & Model 3 \\
\hline \multicolumn{4}{|l|}{ Respondent's education } \\
\hline Low (r) & 1.00 & 1.00 & 1.00 \\
\hline Middle & 0.77 & 0.80 & 0.82 \\
\hline High & 0.99 & 1.07 & 1.13 \\
\hline \multicolumn{4}{|l|}{ Child's education } \\
\hline Low $(r)$ & - & 1.00 & 1.00 \\
\hline Middle & - & 0.78 & $0.68^{* *}$ \\
\hline High & - & $0.69^{*}$ & $0.59^{* *}$ \\
\hline \multicolumn{4}{|l|}{ Sex of best-educated child } \\
\hline Female (r) & - & - & 1.00 \\
\hline Male & - & - & 1.10 \\
\hline Male and female & - & - & 0.87 \\
\hline \multicolumn{4}{|l|}{ Child's proximity to parent } \\
\hline Lives farther away (r) & - & - & 1.00 \\
\hline Coresides & - & - & 0.90 \\
\hline Lives nearby & - & - & 1.01 \\
\hline Age & $1.05^{* *}$ & $1.05^{* *}$ & $1.05^{*}$ \\
\hline $\operatorname{Sex}(1=$ female $)$ & 1.04 & 1.05 & 1.05 \\
\hline Marital status $(1=$ married $)$ & 1.14 & 1.16 & 1.17 \\
\hline Residence $(1=$ rural $)$ & 1.15 & 1.13 & 1.12 \\
\hline Ethnicity (1 = mainland) & 1.08 & 1.15 & 1.18 \\
\hline Number of living children & $1.05^{*}$ & $1.06^{*}$ & $1.08^{*}$ \\
\hline \multicolumn{4}{|l|}{ Income } \\
\hline Lowest (r) & 1.00 & 1.00 & 1.00 \\
\hline Second & 0.91 & 0.70 & 0.96 \\
\hline Third & $0.59^{* *}$ & $0.62^{* * *}$ & $0.62^{*}$ \\
\hline Highest & 0.78 & 0.83 & 0.90 \\
\hline Missing & $1.40^{*}$ & $1.43^{*}$ & $1.42^{*}$ \\
\hline-2 Log likelihood & $2,741.8$ & $2,709.4$ & $2,704.6$ \\
\hline
\end{tabular}

relative to the parent and whether the best-educated child is male, female, or both do not seem to matter. Child's education influences functional status consistently across the other covariates.

When testing for the interactions between child's education and other characteristics, virtually no change to our conclusions was observed, and the interactions are 
generally insignificant. For this reason, we do not report these results in tabular form. The results of the interaction tests suggest that the influences of child's education are not necessarily stronger or weaker when the child is male or female, or when children coreside with or live near their parents. Also, no interaction occurs between child's and parent's education, suggesting that the impact of child's education is consistent regardless of the education of the parent. The one exception to this finding is the interaction between a child's having low education and living far from his or her parent, which is statistically significant when predicting severity of the parent's limitations. In this interaction test, severity appeared to be statistically significantly greater in cases in which the child's education is low and he or she lives far from the parent. On the one hand, this effect may indicate the importance of grown children's education when they do not reside near their parents. On the other hand, it may indicate that children with low levels of education have fewer residence options and may, consequently, need to live far from their parent to obtain work, even if the parent suffers from severe functional limitation. Those who have higher education may be better able to choose to live near their parents and, therefore, be able to assist them with daily tasks.

In order to clarify the effects of the education of parent and child, we have calculated predicted probabilities of having any limitations and of having severe limitations, as shown in Figure 2. We determine this value by applying coefficients to each individual's own characteristics except for education, which we hold constant at specific values. We derive a set of predicted probabilities for each observation, with the results presented in the figure being the sample means for these probabilities. The top section of the figure is a graph of the probability of having any physical limitations according to the aging parent's education across categories of education of the best-educated grown child. The vertical distance between plotted lines can be interpreted as the effect of the parent's education. For instance, when a child has low education, the probability that the parent has limitations is about 0.46 when the parent has a low level of education, a little over 0.4 when the parent has mid-level education, and is reduced to about 0.35 when the parent has high education. The slope of the line can be interpreted as the effect of the child's education. The graph shows that the predicted probabilities decline as the education of the child increases. For instance, when the parent has a low level of education, the probabil- 
Figure 2 Predicted probabilities of an aging parent's having any functional limitations and of having severe limitations, by level of education of parent and of the besteducated adult child, Taiwan

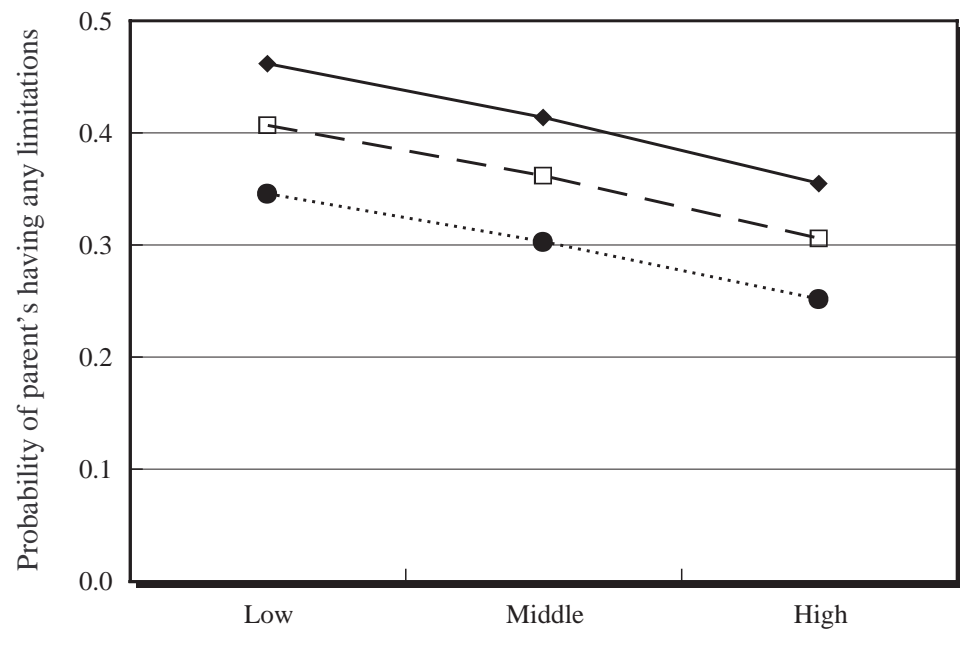

Parent has low education

Child's education
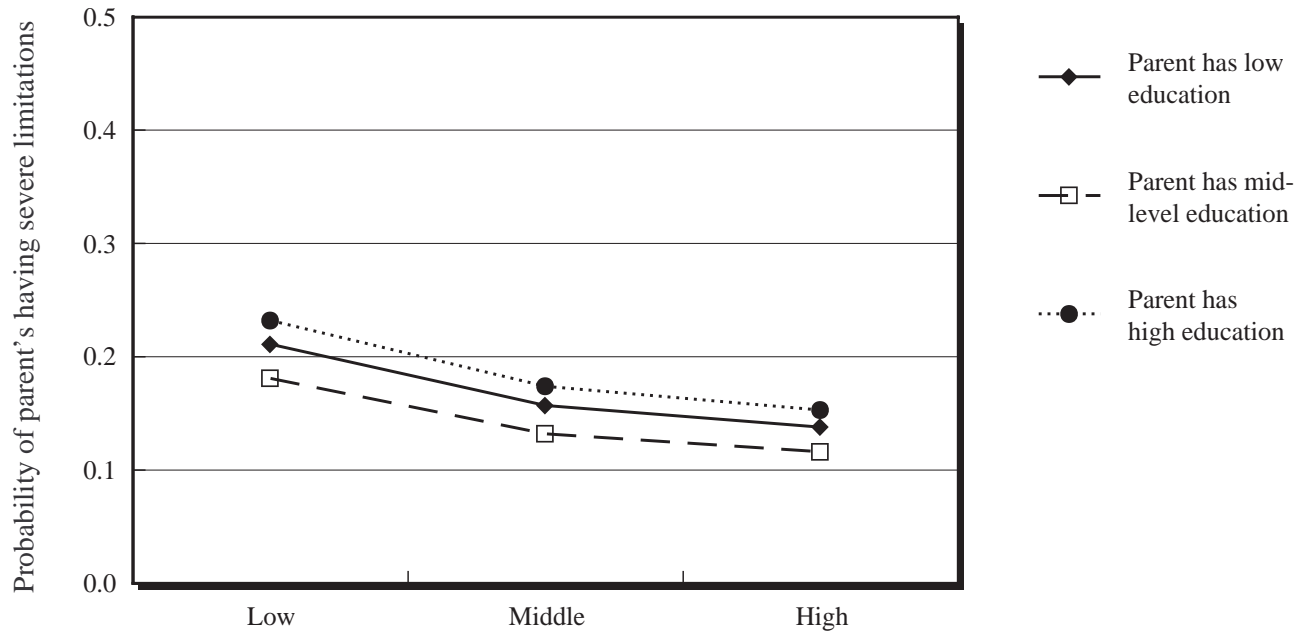

Child's education 
ity of having a functional limitation is about 0.46 when the child also has a low level of education, but decreases to 0.41 when the child has a mid-level education and to about 0.36 when the child has a high level of schooling. The highest probabilities of parent's limitation occur when the parent and child both have low levels of education, and the lowest probabilities occur when the parent and child both have high levels of education.

The bottom section of the figure depicts the predicted probabilities of having severe physical limitations among those aging parents who have any. The vertical distance between lines is negligible, indicating that the parent's education has minimal influence on severity of functional limitations. Some slope decline is seen, however. For example, when the parent has a low level of education, the child's education can reduce the probability of the limitation being severe from a high of about 0.21 when the child also has a low level of education to about 0.14 when the child has a high level of education. The highest probabilities of a parent having severe limitations occur only when the child has a low level of education, whereas the lowest probabilities occur only when the child has a high level of schooling, regardless of the level of the parent's education.

\section{DISCUSSION}

This study has examined the impact of education on the functional status of older adults in Taiwan. It sought to ascertain whether the level of education of a grown child has added effects over and above an older parent's own education by analyzing those effects in terms of the existence and severity of functional limitations. We chose Taiwan because it is characterized by high degrees of family integration despite recent rapid changes in socioeconomic structure. Taiwan is also characterized by wide discrepancies in parent-child educational levels, inequalities suggesting that a grown child may have the ability to bring additional resources to bear on a parent's well-being.

The evidence overwhelmingly supports the hypothesis that the education of a grown child has an added influence on an older parent's functional status. A child's education proved to be important in two ways. First, it had a marked influence on the existence of a functional limitation over and above the parent's education. Second, the child's education was shown to be the crucial determinant of the severity of the parent's limitation. Conversely, the education of an older parent was found to be a statistically 
significant determinant in predicting the existence of functional limitations-a finding that has been found consistently in the literature-but not a determinant of their severity. This distinction has gone unobserved in previous research, likely because existence and severity of limitations have not been isolated in predictive models. The current data show that older adults do not exhibit the sorts of limitations examined in this study, so results from any conceptualization of functional status that do not separate existence and severity would be heavily weighted toward having none versus having any limitations, whereas specific determinants of severity among those who do have limitations might go unnoticed.

As noted above, the significance of an older adult's education in determining the existence of a functional limitation confirms much previous research. Our results for the severity of limitations shed additional light on the determinants of functional status among this sample of older adults and allow us to speculate further on the dynamics involved. The influence of one's own level of education on late-life functional status may be one of prevention. Education is usually acquired early in life, and for older adults the influence of education is a lifelong phenomenon. Undoubtedly, other factors influence an individual's well-being from an early age. These include physical activity and a diet that promotes good health. A broad range of psychosocial phenomena also influences the physical status of older adults, including (i) stress, an important determinant of health (Pearlin 1989); (ii) locus of control or the perception of having control over the course of one's life; (iii) environmental factors, some of which may be related to occupation; and (iv) social support (House et al. 1990). Resources that can be employed throughout life to increase access to and use of health services are also important. Individuals with higher levels of education can better afford high-quality and regular medical care throughout life than can those with less schooling. These influences can serve to ward off potential health problems related to physical functioning in later life.

The associations shown here between grown children's education and severity of parents' physical limitations substantiate the role of family support in determining the progression of those limitations once they arise. In Chinese societies, where filial piety has long been considered a moral obligation, care for the health of an older adult is the responsibility of the family. Once a parent experiences a functional limitation, the re- 
sources, knowledge, and assistance that can be provided by a grown child come into play, and our results appear to show that the type of resources that become mobilized are associated with the education of the best-educated child. Older people who have adult children with similar levels of education will also have the same likelihood of having severe functional limitations. This is so regardless of whether their own education is high or low. Perhaps when a parent is ailing, the quality of grown children's assistance in caregiving and arranging care, the financial resources that they can mobilize, and their advice on how to deal with a given ailment can determine the course of the disorder. In fact, decisionmaking with respect to health care may be the responsibility of the entire family in cases when an older adult's physical functioning begins to fail. Diet, physical activity, and other health-related habits of grown children might also have an impact on the corresponding habits of parents. The development of a functional disorder may lead to a rallying of support around the elder. Family members may, at that time, increase the level of care they provide. Subsequently, the behaviors, attitudes, and knowledge of the wider social network become even more crucial.

Alternative explanations for the associations between a grown child's education and the severity of physical limitations of an aging parent are worth considering. For instance, the association between child's education and the existence of a functional disorder can also suggest an association between parents' goals of educating a child and maintaining their own good health throughout life. In this fashion, older adults who have been concerned about their own health throughout their lives, regardless of their level of education, may tend to be concerned also about the well-being of their family, valuing education for their children and promoting higher learning. This possibility would mean that the associations seen here reflect parents' overall lifestyle choices and value orientations that are geared toward personal achievement for both themselves and their children.

Such an alternative explanation highlights one of the design weaknesses of the current study. Specifically, the potential always exists for varying causal interpretations when cross-sectional data are used, and the validity of causal explanations offered here requires further verification. Other alternative explanations need to be recognized. The residential proximity of parent and child may not be independent of the parent's functional status. Indeed, children may move near or may coreside with aging parents for the pur- 
pose of providing assistance. Where children have received higher education, such a move may reflect their greater choice in residential location; for example, their options for employment near parents may be greater. Such a move may also depend on the availability of other assistance, including that of a spouse or other relatives. Finally, our conceptualization of existence versus severity of functional limitation means that the sample size had to be reduced to one-third of its original size for the second part of the analysis. Although some loss of predictive power resulted, sensitivity analyses confirmed the overall findings.

Despite these limitations, our study suggests several related questions with respect to functional status of older adults elsewhere. In the United States, recent debate has arisen about the nature of and changes in family solidarity (Luescher and Pillemer 1998). Yet even in Western industrial environments, we still often regard the health of older adults as a family concern. Are resources mobilized as widely in light of the differences in family solidarity and integration across different cultural environments? Testing these associations across a variety of societies where attitudes toward the family differ would improve understanding of (i) the effects of social stratification on older adults' health and (ii) the nature and function of family interactions and solidarity. Moreover, determining whether effects are consistent across diverse ethnic groups in countries of heterogeneous culture such as the United States would be of interest. Indeed, certain ethnic groups in the United States, including Asian immigrants, are characterized by norms that lead to high levels of family cohesion and by wide variations in socioeconomic status of parents and their children similar to those found currently in Taiwan.

Whether the contribution of children's education will continue to be significant as Taiwan proceeds with its rapid socioeconomic development is uncertain. The society-wide development currently taking place in Taiwan suggests that future generations of older adults will possess much higher levels of education. To what extent the resources made available through children's education will result in a net contribution to parental health once discrepancies in educational levels between generations begin to decline remains to be seen. Certainly, studies of this nature conducted elsewhere may allow for some speculation in this regard, but longitudinal data must be considered that cover a period of time sufficiently long to account for social changes that affect future cohorts of older adults. 


\section{References}

Agresti, A. 1996. An Introduction to Categorical Data Analysis. New York: John Wiley and Sons.

Antonovsky, A. 1967. "Social class, life expectancy, and overall mortality," Milbank Memorial Fund Quarterly, 45, 31-73.

Asis, M.M.B., Domingo, L., Knodel, J. and Kalyani, K. 1995. "Living arrangements in four Asian countries: A comparative perspective," Journal of Cross-Cultural Gerontology, 10: 145-274.

Camacho, T.C., Strawbridge, W.J., Cohen, R.D. and Kaplan, G.A. 1993. "Functional ability in the oldest old: Cumulative impact of risk factors from the preceding two decades," Journal of Aging and Health, 5: 439-454.

Cornman, J.C., Hermalin, A.I., Roan, C.L. and Chang, M.C. 1996. "Values, accommodations and tensions in Taiwanese families: The perspectives of adult children and their aging parents," Comparative Study of the Elderly in Asia, Research Report Series, No. 96-35. Ann Arbor, MI: Population Studies Center.

Crimmins, E.M. and Saito, Y. 1993. "Getting better and getting worse: Transitions in functional status among older Americans," Journal of Aging and Health, 5: 3-36.

Duffy, M.E. and MacDonald, E. 1990. "Determinants of functional health of older persons," The Gerontologist, 30: 503-509.

Elo, I.T. and Preston, S.H. 1995. "Educational differentials in mortality: United States, 1979-85," Social Science and Medicine, 42: 47-57.

Freedman, V.A. and Martin, L.G. 1998. "Understanding trends in functional limitations among older Americans," American Journal of Public Health, 88: 1457-1462.

Goldman, N., Korenman, S., and Weinstein, R. 1995. "Marital status and health among the elderly," Social Science and Medicine, 40: 1717-1730.

Guralnik, J.M., Land, K.C., Blazer, D., Fillenbaum, G.G. and Branch, L.G. 1993. "Educational status and active life expectancy among older blacks and whites," The New England Journal of Medicine, July 8: 110-116. 
Hermalin, A.I., Ofstedal, M.B. and Chang, M.C. 1996. "Types of support for the aged and their providers in Taiwan." In T.K. Hareven (ed.), Aging and Generational Relations Over the Life Course: A Historical and Cross-Cultural Perspective, New York: Walter de Gruyter, pp. 400-437.

Hermalin, A.I., Ofstedal, M.B. and Lee, M.L. 1992. "Characteristics of children and intergenerational transfers," Comparative Study of the Elderly in Asia, Research Report Series, No. 92-21. Ann Arbor, MI: Population Studies Center.

House, J.S., Kessler, R.C., Herzog, R.A., Mero, R.P., Kinney, A.M. and Breslow, M.J. 1990. “Age, socioeconomic status, and health," The Milbank Quarterly, 68: 383-411.

House, J.S., Lepkowski, J.M., Kinney, A.M., Mero, R.P., Kessler, R.C. and Herzog, R.A. 1994. "The social stratification of aging and health," Journal of Health and Social Behavior, 35: 213-234.

Kaplan, G.A., Strawbridge, W.J., Camacho, T. and Cohen, R.D. 1993. "Factors associated with change in physical functioning in the elderly: A six-year prospective study," Journal of Aging and Health, 5: 140-153.

Katz, S., Ford, A.B., Moskowitz, R.W., Jackson, B.A. and Jaffe, M.W. 1963. “Studies of illness in the aged: The index of ADL, a standardized measure of biological and psychosocial function," Journal of the American Medical Association, 185: 914-919.

Kelly-Hayes, M., Jette, A.M., Wolf, P.A., D’Agostino, R.B., and Odell, P.M. 1992. "Functional limitations and disability among elders in the Framingham Study," American Journal of Public Health, 82: 841-845.

Kitagawa, E.M. and Hauser, P.M. 1973. Differential Mortality in the United States: A Study of Socioeconomic Epidemiology. Cambridge, MA: Harvard University Press.

Lawton , M.P. and Brody, E. 1969. "Assessment of older people: Self-maintaining and instrumental activities of daily living," The Gerontologist, 9: 179-186.

Link, B.G. and Phelan, J. 1995. "Social conditions as fundamental causes of disease," Journal of Health and Social Behavior, Extra issue: 80-94.

Luescher, K. and Pillemer, K. 1998. "Intergenerational ambivalence: A new approach to the study of parent-child relations in later life," Journal of Marriage and the Family, 60: 413-425. 
Lynch, J.W., Kaplan, G.A. and Shema, M.S. 1997. "Cumulative impact of sustained economic hardship on physical, cognitive, psychological, and social functioning," The New England Journal of Medicine, 337: 1889-1895.

Manning, W.G., Duan, N. and Rogers, W.H. 1987. "Monte Carlo evidence on the choice between sample selection and two-part models," Journal of Econometrics, 35: $59-82$.

Marmot, M.G., Rose, G., Shipley, M. and Hamilton, P.J.S. 1978. "Employment grade and coronary heart disease in British civil servants," Journal of Epidemiology and Community Health, 32: 244-249.

Nagi, S.Z. 1976. An epidemiology of disability among adults in the United States," Milbank Memorial Fund Quarterly, Health and Society, 54: 439-468.

_. 1991. "Disability concepts revisited: Implications for prevention." In A.M. Pope and A.R. Tarlov (eds.), Disability in America: Toward a National Agenda for Prevention, Washington, D.C.: National Academy Press, pp. 309-327.

Ortmeyer, C.F. 1974. "Variations in mortality morbidity, and health care by marital status." In C.E. Erhardt and J.E. Berlin (eds.), Mortality and Morbidity in the United States, Cambridge, MA: Harvard University Press, pp. 159-188.

Pappas, G., Queen, S., Hadden, W. and Fisher, G. 1993. "The increasing disparity in mortality between socioeconomic groups in the United States, 1960 and 1986," The New England Journal of Medicine, 329: 103-109.

Pearlin, L.I. 1989. "The sociological study of stress," Journal of Health and Social Behavior, 30: 241-256.

Preston, S.H. and Elo, I.T. 1995. "Are educational differentials in adult mortality increasing in the United States?" Journal of Aging and Health, 7: 476-496.

Robert, S.A. and Li, L.W. 2001. "Age variation in the relationship between community socioeconomic status and adult health," Research on Aging, 23: 233-258.

Rogers, R.G., Rogers, A. and Belanger, A. 1992. "Disability-free life among the elderly in the United States: Sociodemographic correlates of functional health," Journal of Aging and Health, 4: 19-42. 
Ross, C.E. and Wu, C.L. 1995. "The links between education and health," American Sociological Review, 60: 719-745.

— 1996. "Education, age, and the cumulative advantage in health," Journal of Health and Social Behavior, 37: 104-120.

Ross, C.E., Mirowsky, J. and Goldsteen, K. 1990. "The impact of the family on health: The decade in review," Journal of Marriage and the Family, 52: 1059-1078.

Silverstein, M. and Bengston, V.L. 1997. "Intergenerational solidarity and the structure of adult child-parent relationships in American families," American Journal of Sociology, 103: 429-460.

Simonsick, E.M., Kasper, J.D., Guralnik, J.M., Bandeen-Roche, K., Ferrucci, L., Hirch, R., Leveille, S., Taina, R. and Fried, L.P. 2001. "Severity of upper and lower extremity functional limitation: Scale development and validation with self-report and performance-based measures of physical function," Journal of Gerontology, 56: S10-S19.

Taiwan Provincial Institute of Family Planning. 1989. "1989 Survey of Health and Living Status of the Elderly in Taiwan: Questionnaire and survey design," Comparative Study of the Elderly in Four Asian Countries, Research Report No. 1. Taiwan Provincial Institute of Family Planning and Ann Arbor, MI: University of Michigan, Population Studies Center and Institute of Gerontology.

Townsend, P. and Davidson, N. 1982. Social Inequalities in Health: The Black Report. Harmondsworth: Penguin Books.

Verbrugge, L.M. 1989. "The twains meet: Empirical explanations for sex differences in health and mortality," Journal of Health and Social Behavior, 30: 282-330.

Verbrugge, L.M. and Jette, A.M. 1994. "The disablement process," Social Science and Medicine, 38: 1-14.

Williams, D.R. 1990. "Socioeconomic differentials in health: A review and redirection," Social Psychology Quarterly, 53: 81-99.

Winkleby, M.A., Jatulis, D.E., Frank, E. and Fortmann, S.P. 1992. "Socioeconomic status and health: How education, income and occupation contribute to risk factors for cardiovascular disease," American Journal of Public Health, 82: 816-820. 


\section{POLICY RESEARCH DIVISION WORKING PAPERS}

Recent Back Issues

1999

*120 John Bongaarts, "The fertility impact of changes in the timing of childbearing in the developing world."

*121 James F. Phillips, Wendy L. Greene, and Elizabeth F. Jackson, "Lessons from community-based distribution of family planning in Africa."

122 Mark R. Montgomery, "Mortality decline and the demographic response: Toward a new agenda."

*123 Mark R. Montgomery, Mary Arends-Kuenning, and Cem Mete, "The quantity-quality transition in Asia."

124 Barbara S. Mensch, Wesley H. Clark, Cynthia B. Lloyd, and Annabel S. Erulkar, "Premarital sex and school dropout in Kenya: Can schools make a difference?"

125 John Bongaarts and Rodolfo A. Bulatao, "Completing the demographic transition."

126 Geoffrey McNicoll, "Population weights in the international order."
127 Cynthia B. Lloyd, Carol E. Kaufman, and Paul Hewett, "The spread of primary schooling in subSaharan Africa: Implications for fertility change."

128 John B. Casterline, "The onset and pace of fertility transition: National patterns in the second half of the twentieth century."

129 Mark R. Montgomery, Michele Gragnolati, Kathleen Burke, and Edmundo Paredes, "Measuring living standards with proxy variables."

130 Bamikale Feyisetan and John B. Casterline, "Fertility preferences and contraceptive change in developing countries."

131 Martin Brockerhoff, "Urban growth in developing countries: A review of projections and predictions."

132 Omaima El-Gibaly, Barbara Ibrahim, Barbara S. Mensch, and Wesley H. Clark, "The decline of female circumcision in Egypt: Evidence and interpretation."

* No longer available 
133 Mary Arends-Kuenning and Sajeda Amin, "The effects of schooling incentive programs on household resource allocation in Bangladesh."

134 John Bongaarts and Charles F. Westoff, "The potential role of contraception in reducing abortion."

135 John B. Casterline and Steven W. Sinding, "Unmet need for family planning in developing countries and implications for population policy."

*136 Carol E. Kaufman, Thea de Wet, and Jonathan Stadler, "Adolescent pregnancy and parenthood in South Africa."

137 Valerie L. Durrant and Zeba A. Sathar, "Greater investments in children through women's empowerment: A key to demographic change in Pakistan?"

138 Sajeda Amin, Alaka Malwade Basu, and Rob Stephenson, "Spatial variation in contraceptive use in Bangladesh: Looking beyond the borders."
139 Geoffrey McNicoll, "Managing population-environment systems: Problems of institutional design."

140 Barbara S. Mensch, Barbara L. Ibrahim, Susan M. Lee, and Omaima ElGibaly, "Socialization to gender roles and marriage among Egyptian adolescents."

141 John Bongaarts and Elof Johansson, "Future trends in contraception in the developing world: Prevalence and method mix."

142 Alaka Malwade Basu and Sajeda Amin, "Some preconditions for fertility decline in Bengal: History, language identity, and an openness to innovations."

143 Zeba Sathar, Cynthia B. Lloyd, Cem Mete, and Minhaj ul Haque, "Schooling opportunities for girls as a stimulus for fertility change in rural Pakistan."
144 John Bongaarts, "Household size and composition in the developing world."

145 John B. Casterline, Zeba A. Sathar, and Minhaj ul Haque, "Obstacles to contraceptive use in Pakistan: A study in Punjab."
146 Zachary Zimmer, Albert I. Hermalin, and Hui-Sheng Lin, "Whose education counts? The impact of grown children's education on the physical functioning of their parents in Taiwan." 

